\title{
Several Principles Followed by Construction of the University Academic Leaders
}

\author{
Rongxiang Guo ${ }^{1, a}$, and Hui $\mathrm{Xu}^{2, \mathrm{~b}^{*}}$ \\ ${ }^{1}$ Administrative Office of Teaching Quality Management, Nantong University, Nantong, 226019, \\ China \\ ${ }^{2}$ School of Computer Sci. \& Tech, Nantong University, Nantong, 226019, China \\ aguo.rx@ntu.edu.cnl, ${ }^{b^{*}}$ xu.h@ntu.edu.cn ( ${ }^{\star}$ Corresponding author)
}

Keywords: University, Academic leader, Construction, Principles.

\begin{abstract}
The construction of university academic leader should lay equal stress on both training and introduction, both spiritual motivation and material motivation, both cultural development and institutional improvement, both teaching level and level of scientific research and both ability and education background. Only these principles are followed, a academic leader team with excellen academic attainments, academic literacy, academic awareness, and teaching level can be built to meet the need of development of the university.
\end{abstract}

\section{Introduction}

The quality of higher education has been increasingly concerned sicence the the coming era of mass higher education. It has become the consensus for the higher education to establish the necessary quality guarantee system and mechanisms in order to ensure the quality of higher education personnel training [1]. Then, undoubtedly it is very important to establish a high qualified academic leader team. High-quality student can not be cultivated without quality teachers. The quality and high level of the university teachers can not increases without high-level academic leaders.

Currently, the problems exsiting in the construction of academic leaders is as following: attach importance to introduce and make light of training; attach importance to material motivation and make light of moral encouragement; attach importance to institutional improvement and make light of cultural construction; attach importance to scientific research level and make light of teaching level; attach importance to education background and make light of ability. For these incorrect ideas and practices, we think the several following principles should be abided by in building university academic leaders.

\section{Principles Should be Followed in Constructing the University Academic Leaders}

\subsection{Both Training and Introduction}

\subsubsection{Introduction}

Today's world, competition for talent is becoming increasingly fierce. Many universities put a lot of energy, human and financial resources to build their academic leader team through introduction and take it as a major work. For some top-notch personnel, such as academicians, young "Changjiang Scholar", "333 Project" talents, etc., many universities promise them house, some ten thousand annual salary, special laboratories and scientific research start-up funding, in order to intruduce them. It does spared no expense. Even more some universities formed a special team to excavate and grab people everywhere.

Indeed, the introduction of university academic leaders has many positive significance, such as: fast effect, creating a good atmosphere of respecting teachers; inspire young teachers quickly grow; spur university make good use of academic leaders and retain academic leaders; make up for insufficient disciplines. But there are some negative effects. For example, better condition the university has, better the area in which the university is, more ability and strength the university have, 
more attractive to the first-class academic leaders. Then the strong become stronger and the weak become weaker, the enthusiasm for the weak cultivate academic leaders is reduced.

\subsubsection{Training}

It should be noted that our higher education quality, discipline construction, and level of teaching and scientific research, compared with developed countries, there are a relatively large gap. It means many academic leaders are needed by us, but the introduction is only a flow of academic leader moving from his university to others', the aggregate does not increase and the overall level does not improve, the shortage of academic leader will still exist. So, the foundation is to training academic leader. It is not a night thing for an ordinary teacher become an academic leader, it needs a process and a longer time. How to cultivate the leader? Domestic and international human resource management scholars proposed an idea of "career management", it provides an effective way to cultivate and foster outstanding academic leaders, as well as to retain academic leaders.

The so-called "career management" simply means that the organization and employees jointly make and implement the plan of personal growth and personal development based on both sides needs of developing from the goal of the organization and the employee capabilities or interests in order to help staff career development [2]. Career management poses a challenge to traditional management mode of academic leaders. In traditional mode, a academic leader is regarded as a common factor based on the static needs of school, In Career Management, university gives the design of the growth of each academic leader throughout his whole career, under the guidance of the dynamic school organizational goal, and provides convenience of information, consultation, financing, training and time for him to implement his career planning. Then Personal Career Goals of academic leaders and objectives of training school teachers achieve simultaneously.

Career Management effectively put the various elements of Human Resources Management together organically and systematacially. The academic leader realizes that he is not only managed by the school, but a university master is, they are able to participate in the management and responsible for his own future. The personal wishes are respected and are helped to achieve them. Career Management combines the good use with training of the academic leader, it is helpful to arouse the initiative and enthusiasm of academic leaders, improve the quality of their work and their life, realize their wish to success; it is also contribute to realization of training academic leader, and achieve the "win-win" purpose the individual and university.

\subsubsection{Introduction and Training}

University promotes the flow of excellent teachers through the introduction of academic leaders, which can make the existing outstanding academic leaders give full play their potentia. But the introduction of academic leaders can be only as a auxiliary and temporary measures to buffer the problem, the training of academic leaders is foundation. As a visionary university leader, he should focus on cultivating academic leaders. Meanwhile, the state should take appropriate measures to start the appropriate mechanism to support the rational flow, and a more encouraging for university to train academic leaders. Thus, good atmosphere of training self talents would be formed.

\subsection{Both Material Incentives and Spiritual Incentives}

\subsubsection{Material Motivation}

Incentives as a psychology term, refers a mental process of stimulating people's motivation [3]. Incentives are often used in cultivating university academic leaders to make them in a excited mental state, to mobilize their enthusiasm and initiative, to develop their potential and creativity, and spur their rapid growth. But most universities lay more emphasis on material incentives, especially after the reform of personnel salary allocation.

The University link up teachers' teaching, research performance and wages, bonuses, etc. with their material benefits in order to strengthen the effect of material incentives. Admittedly, after this reform, harder academic leader work, more effort they make, thicker atmosphere of academic research is, more achievements in scientific research have. But at the same time, we also see that the 
spiritual incentives are weaken, it seems that kind of material incentive trends to replace the mental stimulation.

\subsubsection{Spiritual Motivation}

Spirit incentives mobilize people's intrinsic motivation inspired by meeting people's spiritual needs. Substance is tangible, material incentive is easy to implement; the spirit is invisible, how to carry through the spiritual incentives? In fact, there are many methods, here are a few cases.

(1) Achievement motivation. Here, incentive is to help academic leaders get achievement in order to satisfy their psychology of eager for self-realization and contribution. The university creates a variety of conditions conducive to academic leaders' successful career depending on their different needs, meets their reasonable aspirations, and mobilizes their initiative and enthusiasm of teaching and research.

(2) Interest excitation. Here, incentive is to help academic leaders cultivate noble interest conducive to social progress, individual physical and mental health. Interest is the power of action. The university encourages academic leaders interested in social progress, so that they really aware of meaning and purpose of their work in mentality inwardly, and thus the various tasks successfully complete as a fun and a proud.

(3) Example excitation. Here the incentive is to set examples for academic leaders. As the saying goes "if one sheep leaps over the ditch, all the rest will follow". The university recommends and broadcasts well-recognized figures, all they have the feature of noble quality, progressive thought, diligent work, and outstanding contribution, to stimulates academic leaders to learn advanced model, imitate models' behavior, absorb models' the merits, spur oneself efforts, and get continuous improvement.

(4) Race excitation. Here the incentive is to provide various competitions for academic leaders. The university organizes the competitions such as learning competitions, skills competitions, sports competitions, teaching competition, etc., for teachers at all age and all levels, in order to make them learn from each other, mutual infection, mutual encouragement, and then all the community cohesion, collective responsibility, sense of honor are enhanced.

(5) Humane Care Incentive. Here the incentive is show solicitude for academic leader in political process, work and life. The university creates all favorable conditions for majority of academic leaders, and then makes them learn his strong, and use his strong; care about their work and life, help them solve real-life difficulties, warm their hearts with boiling emotions, arouse their enthusiasm and initiative for work. All of these help academic leaders to put more energy into teaching and research work.

\subsubsection{Material Motivation and Spiritual Motivation}

According to Maslow hierarchy of needs theory [4], people needs can not stay in the level of material need. One wants to become self-fulfilling and feel the greatest satisfaction only when both their material and spiritual needs are met. University is the convergence of high-quality people with the highly educated and the high title of a technical post, they are particularly strong on the spiritual needs. Therefore, in building the university academic leaders team, mental stimulation not only should not be reduced, but also should be strengthened. Material incentives will play the role material incentives can’t play.

\subsection{Both Cultural Construction and Institutional Improvement}

\subsubsection{Institutional Improvement}

With the advance of our legal system, the work of the University also embarks on institutionalized and standardized way. Establish and improve various rules, measures of fair competition and incentive mechanism, has become prerequisite and guarantee for a university to build academic leaders team. Although the management system is exhaustive and scienctific, it is impossible to encompass everything and be in omnipresent, drilling loopholes of the system is entirely possible. If the system is set too fine to prevent loophole, it must loses its flexibility and resilience, and then teachers became work machine. Moreover, if the system is implemented entirely through hard constraints, very close to death and serious, the conflict of the teacher will rise and management 
effect will be worse. If the institution building is a rigid management process, then, the corresponding cultural construction is a flexible management process, both hardness and softness will produce the best management results.

\subsubsection{Cultural Construction}

Spiritual is necessary for people more or less, especially for academic leaders. Universities also need to have their own spirit. The construction of academic leaders needs positive atmosphere and environment suitable for bring out the people's potentials. Such spirit, atmosphere and environment only can be built through the culture. The core of the university culture should be "respect, understand, care about and train people". Under this good cultural atmosphere [5], academic leaders will be in standard of behavior and invisible constraints on a healthy moral rule; work ethic and sense of responsibility is cultivated to implement rules and regulations from the heart of consciousness; the willing is unified, teachers wisdom and strength are gathered, and cohesion and solidarity is enhanced, ultimately the school's overall goal is achieved.

\subsubsection{Institutional Improvement and Cultural Construction}

From the above, in building of university academic leaders team, implementating institutional management is the evolution of the rule of man from rule of law; conducting cultural construction is to make the implementation of the system forcibly sublimate to consciousness. Implementation of rigid management is the foundation that allows the building of academic leaders to run orderly and have rules to follow. Implementation of flexible management is supplementary and sublimation of rigid management. Rigid and flexible, hardness with softness, can complement each other, both combination can play optimal performance in building of university academic leader team.

\subsection{Both Teaching Level and Scientific Research Level}

\subsubsection{Scientific Research}

Some universities have a tendency to focus on research over teaching in building the academic leader team for the following reasons.

(1) Society pays more and more attention to the level of scientific research of a university. When people measure the level of the university brand, they often take their first look at the number and level of scientific research, the quantity and quality of papers published. It leads to university hope their teachers produce more good scientific research achievements to enhance its brand.

(2) The level of scientific research can be measured by calculating quantity or number of achievements, this make it comparable. Relatively, the level of teaching is difficult to be quantified or difficult to be measured by an intuitive way, that means it is ambiguity or no comparable. Therefore, the University regards intuitive and dominant scientific level as important, look down on the long-term, implicit level of teaching or improvement of teaching quality. This is reflected in building of academic leader team.

(3) The university has a duty to develop science and serve social, those work more rely on academic leaders and high level scientific research. It determinates that academic leaders must engage in a lot of research work. Through scientific research, improve their academic level to take more responsibility for social development; enrich the content of teaching to promote the quality of teaching and improve the quality of personnel training; organize students to participate in research projects or scientific research activities to develop students' research capabilities, hands-on ability to solve practical problems and creative skills.

\subsubsection{Teaching}

We should see the university's basic mission is to nurture talent. Highly qualified specialists are trained mainly through the teaching and learning activities. Thus, teaching is the main task of university teachers. Each academic leader must undertake teaching task according to the professional settings, training target and teaching outline, follow the rules of development of students' physical and mental and internal basic education law, actively explore effective teaching methods, make efforts to improve the teaching quality.

\subsubsection{Scientific Research and Teaching}


University teaching and research activities are complementary and mutually reinforcing, closely integrated, there is an intrinsic link between them. Teaching mostly passes on the predecessors' research results to students in planned, purposeful and systematic manner, so that students can master the objective laws; research mainly explore new objective laws based on existing knowledge and the necessary conditions, so that student can gain new knowledge.

From the student's perspective, innovation is not a fantasy without any foundation, it must be built on the basis of certain knowledge. Students must master basic theory and professional knowledge in order to engage in scientific research under the guidance of teachers. In this sense, the teaching is tha base of scientific research. From the view of human cognitive activities, the various professional teaching only can be carried out after the practice experience is summarized to the theory through scientific research. In this sense, research is the source of teaching.

In addition, building the University's academic leaders team should adhere to both ability and qualifications, both titles and performance principles.

\section{Summary}

In short, building university academic leader team is very important because academic leaders shoulder the historical responsibility of transfer and development human scientific cultural knowledge and training national builders and successors. To build the academic leader team should free from the external environment, not affect by material gain, conforms the internal logic and requirements of discipline construction, and keep to rules of talent growth, then the exquisite team of academic leader excellent in scientific attainments, academic attainment, academic awareness, and teaching level will be built.

\section{Acknowledgement}

This research was financially supported by the National Education Science during the 12th Five-Year Plan Period -- the Key Program of Ministry under Grant No. DIA110286, Ministry Planning Fund for Development of education, Humanities and Social under Grant No. 11YJA880027, and the Key Project of Jiangsu Province Higher Education Reform under Grand 2011JSJG031.

\section{References}

[1] L. Cai: Study on selection, training and construction of evaluation mechanism of university academic leader, Journal of Education Exploration, 5(2010), p. 106-107

[2] S. B. Ma: Truly reflect the people-oriented management: Career Management, Journal of Nanjing University od Science and Technolog, vol.2(2009), p. 52-55.

[3] B. H. Lan: Magement of regarding people as the center, Guangdong economic Publishers(2007), p. 309-334.

[4] J. A. Simons, D. B. Irwin and B. A. Drinnien: Psychology - The Search for Understanding, West Publishing Company, New York(1987).

[5] J. L. Chen: Art of leadership of university, Northwest University Publishers(2005), p. 53-63. 